\title{
Stereological Evaluation of the Brains in Patients with Parkinson's disease Compared to Controls
}

\author{
Zahra Heidari ${ }^{1,2}$, Ali Moghtaderi ${ }^{3}$, Hamidreza Mahmoudzadeh-Sagheb ${ }^{1,2^{*}}$, \\ Enam Alhagh Charkhat Gorgich ${ }^{2,4}$
}

\author{
1. Infectious Diseases and Tropical Medicine Research Center, \\ Zahedan University of Medical Sciences, Zahedan, Iran \\ 2. Department of Histology, School of Medicine, Zahedan University of \\ Medical Sciences, Zahedan, Iran \\ 3. Department of Neurology, School of Medicine, Zahedan University \\ of Medical Sciences, Zahedan, Iran \\ 4.Student Scientific Research Center, Zahedan University of Medical
}

Sciences, Zahedan, Iran

\begin{abstract}
Parkinson's disease (PD) is a chronic and progressive neurological disorder. A tetrad of bradykinesia, rigidity, tremor and postural instability are the core features of the disease. The aim of this study was to evaluate stereological changes in the brain of patients with PD and compare them with that of healthy controls. This case-control study was conducted on 29 patients with PD and 12 controls $(C)$ in Zahedan, Iran. All subjects enrolled into the study through the convenience sampling method. MRI images of the brains of two groups in frontal and sagittal axis with consecutive $5 \mathrm{~mm}$ distance slices were captured. Parameters including total volume (V) and volume density (Vv) of different parts of the brain were estimated based on Cavalries' point counting stereological method. To analyze the data, descriptive statistics, Mann-Whitney U-Test applied for comparing the PD and C groups were used. Significance level was set at $p<0.05$. Our study showed that the volume of the brain and total volume and volume density (Vv) of cerebral hemispheres, cerebellum, ventricles, hippocampus, pons, mid brain and superior cerebellar peduncles in the PD group did not indicate significant difference from the control group. Total volume of brain stem in PD group wasn't significantly different from the control group. The volume density of brain stem $(p=0.012)$ and total volume and volume density of middle cerebellar peduncle $(p<0.0001)$ in PD group were significantly larger than the control group. This study shows that PD stereological parameters related to volume and volume density of middle cerebellar peduncle and volume density of brain stem were significantly larger in patients compared to the controls. Therefore, stereological parameters can be used for early diagnosis and probably for follow-up in patients with PD.
\end{abstract}

Keywords: stereology, Parkinson's disease, MRI, brain, quantitative analysis

Received: $18^{\text {th }}$ January 2017; Accepted: 23 ${ }^{\text {rd }}$ February 2017; Published: $16^{\text {th }}$ May 2017

*Corresponding author: Hamidreza Mahmoudzadeh-Sagheb, Department of Histology, Zahedan, Iran, e-mail: histology@ymail.com 


\section{Introduction}

Parkinson's disease (PD) is one of the most common and partially treatable degenerative movement disorders. It is the second common age-related neurodegenerative disease after Alzheimer's disease. PD is defined as progressive and irreversible degeneration of dopaminergic neurons in the substantia nigra pars compacta (SNPC) $(1,2)$. Progressive degeneration of those neurons causes reduced dopamine production in the striatum. This event leads to motor and behavioral disorders in the PD patients (3). Usually it is idiopathic in etiology; however, other causes such as medications, toxins, vascular infarction, life styles, head trauma, infections and inheritance are reported to be the causative agents. It has been shown that the oxidative stress plays a crucial role in PD pathogenesis (3). Basically, loss of dopaminergic neurons in PD patients is the main reason for tremor at rest, bradykinesia, rigidity, slow involuntary reactions and postural imbalance (4). At first, symptoms appear slowly and, seem to be due to normal aging, however, after years of progression, clinical features of the disease are well established and make the diagnosis easy and feasible. Disease progression may be more rapid in some people. Other than clinical features, diagnosis is not possible based on routine imaging and laboratory findings. Therefore, in those patients early diagnosis based on detection of quantitative changes in brain MRI results, is incredibly crucial (5).

Although PD is a common disorder in elderly, it is rare before age 50, but its incidence increases in elderly people (2). Its prevalence dramatically increases after 60 , as 1 to $2 \%$ of the people are affected in this age (6). Worldwide, studies revealed that the prevalence of PD ranges from 31 to 347 per 100,000 people. In US it is about 150 per 100,000 in all ages and reaches to approximately 800 per 100,000 at 70 to 85 (7). Epidemiological studies in Iran showed that its prevalence is medium -to-high and estimated to be more than 200 per 100,000 people (8). It is actually more frequent in men than women and progresses faster in male than female patients (5).

Nowadays, magnetic resonance imaging (MRI), positron emission tomography (PET) and single-photon emission computed tomography (SPECT) are available and MRI is commonly used for clinical trials to differentiate idiopathic PD from other types of PD such as vascular and other structural lesions. Moreover, reduced $\mathrm{T}_{2}$ and FLAIR hyperintense signals in MR imaging helps to differentiate PD from multiple systemic atrophy (MSA) and progressive supranuclear palsy (PSP). Despite the presence of diagnostic criteria for diagnosis of PD and atypical parkinsonian disorders (APDs) such as MSA, MSA-C, PSP and corticobasal degeneration (CBD), clinical differentiation of these diseases is challenging (9). Therefore, differentiating between PD and APDs for clinical evaluation of disease and response to treatment and evaluation of prognosis has a determinative role. In degenerative disorders such as PD and Alzheimer's disease that are associated with selective regional volume loss (atrophy), quantitative volumetric brain measurements by MRI images for clinical applications are very useful and practical (10). Quantitative volumetric measurements by MRI are used widely for determining the disease progression and response to treatment (11).

Stereological methods which are widely used in many fields of medical sciences, may also be useful in neuro-morphological studies in central nervous system (12). Estimation of volumes of various brain regions, numbers of neurons and glial cells, length of vessels and nerve fibers in histological sections are the major parameters reported in other studies (13). It can also be applied on MRI images to obtain quantitative data useful for early detection or for following up the clinical course of chronic and progressive 
diseases and finally the effects of drugs and response to treatment (14).

In many studies, stereological methods suggest approaches for measurement of the quantitative parameters of brain in degenerative diseases like as PD, AD and schizophrenia, neuropsychiatry and normal aging $(15,16)$. In most cases foundation of PD diagnosis were based on clinical findings but MRI-based volumetric was used for evaluating the volume and morphological changes of this neurological disease (16, 17). Stereological measurements are relatively simple, cheap, unbiased and reliable techniques based on point counting approach useful for differentiating PD from other neurodegenerative diseases (18). Therefore, the aim of this study was to investigate-stereological changes of different parts of the brain in patients with Parkinson's disease compared to control group.

\section{Materials and Methods}

\section{Patients}

In this case-control study, stereological changes of the brain in 29 patients with Parkinson's disease were compared to 12 healthy individuals without any history of neurological or psychiatric disorders.

The study was performed after getting approval of the Ethics Committees of Zahedan University of Medical Sciences (No: 90-518). Written informed consent was obtained from all participants before starting the study according to the protocol of the Dean for Research Affairs of the university.

Patients were entered the study based on clinical diagnosis of PD. The disease should be diagnosed at least 6 months earlier in the University hospital clinic by one of the authors. Other mimicking disorders were ruled out by standard diagnostic procedures and/or clinical findings. Demented patients as well as alcoholics and smokers were excluded from the study.

\section{MRI and stereological procedure}

The study was performed on high-resolution 1.5 Tesla MRI Scanner (GE systems, Paris). FLAIR (Fluid Attenuated Inversion Recovery) MR images from the brains of patients and control groups in frontal and sagittal axis with consecutive $5 \mathrm{~mm}$ slides thickness without gap were prepared. Then stereological grids containing organized points were superimposed on brain MRI images randomly and points hit to desired brain structures estimated by using Cavalieri's point counting method (19). (Figure 1)

Cavalieri's point counting method was employed to estimate the volume of the brain and its components using the formula:

$$
\mathrm{v}=\frac{\sum_{i=1}^{m} \mathrm{p} \times \mathrm{a} / \mathrm{p} \times \mathrm{t}}{M^{2}}
$$

Where $\mathrm{V}$ is the estimation of the volume of any desired object, $\sum \mathrm{P}$ is the sum of the number of points hitting that object slices, $a / p$ is the area associated with each point in the stereological grid, $\mathrm{t}$ is the mean distance between the captured slices, and $M$ is the linear magnification of the image. Then, an estimate of the volume density $(\mathrm{Vv})$ of the brain components in the reference space (total brain) was obtained using:

$\mathrm{Vv}=\mathrm{P}$ (part)/P (ref)

Where, $\mathrm{P}$ (part) is the number of test points falling in each component profiles and $\mathrm{P}$ (ref) is points hitting to the total brain (20).

\section{Statistical Analysis}

The authors made a standardized report sheet in which collected data were entered stepby-step as described earlier. All statistical analyses were performed in SPSS software for Windows (version 21, Chicago, IL, USA). After an evaluation of assumption for normal distribution we calculated values of arithmetic mean, standard deviation and $95 \%$ confidence interval for the mean of different variables. Then the authors 


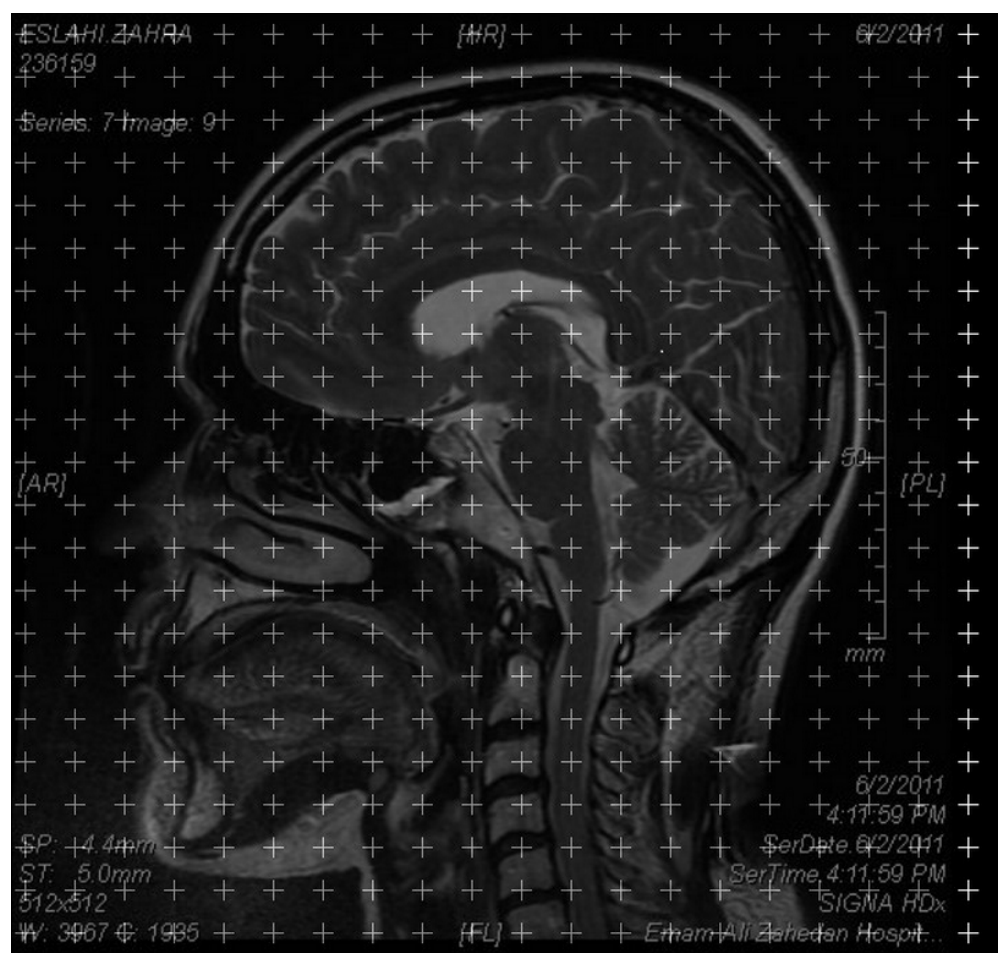

Figure 1. Point counting method on MR image from a sagittal section of the human brain

carried out descriptive statistics to perform demographic analyses, and inferential statistics by using unpaired two samples $t$-test and nonparametric test of Mann-Whitney $U$ for comparing age, sex, and other measured values between two groups. Comparisons were labeled statistically significant at the conventional $\mathrm{p}$-value of less than 0.05 .

\section{Results}

The results showed that the mean age for patients was $60.1 \pm 14.39$ and for healthy controls was $60.17 \pm 9.49$ year. The ratio of males to females in the PD group was 20 to 9 and in healthy control group 8 to 4 . There were no significant differences in terms of mean age and gender between both groups $(p>0.05)$.

The current study indicated that there were no significant differences in terms of total brain volume, total volume and volume density of each cerebral hemisphere, cerebellum, ventricles, hippocampal formation and pons between PD and healthy study groups ( $p>0.05)$. The volume density of brain stem in the PD group revealed $18.75 \%$ increment compared to the control individuals. The total volume and volume density of middle cerebellar peduncle in PD group were respectively $96.7 \%$ and $100 \%$ greater than controls $(\mathrm{p}<0.0001)$. (Table I)

\section{Discussion}

In the current study we investigated the stereological changes of different parts of the brain in patients with PD and compared them with a healthy control group. The findings showed that the total brain volumes, total volume and volume density of the cerebral hemispheres, cerebellum, ventricles, hippocampus 
Table I. Stereological parameters of different parts of the brain in Parkinson's (PD) and control groups

\begin{tabular}{|c|c|c|c|c|}
\hline Stereological parameters & $\begin{array}{c}\text { PD group } \\
(n=29)\end{array}$ & $\begin{array}{c}\text { Control group } \\
(\mathrm{n}=12)\end{array}$ & $\begin{array}{l}\text { Difference } \\
\text { percentage }\end{array}$ & $p$-value \\
\hline Total brain volume & $1249.3 \pm 159.32$ & $1319.4 \pm 112.37$ & -5.31 & NS \\
\hline $\begin{array}{l}\text { Cerebral hemispheres } \\
\text { Total volume }\left(\mathrm{mm}^{3}\right) \\
\text { Volume density }(\%)\end{array}$ & $\begin{array}{c}867.9 \pm 114.45 \\
69.9 \pm 7.60\end{array}$ & $\begin{array}{c}937.1 \pm 120.76 \\
34.54 \pm 2.41\end{array}$ & $\begin{array}{l}-7.38 \\
-1.82\end{array}$ & $\begin{array}{l}\text { NS } \\
\text { NS }\end{array}$ \\
\hline $\begin{array}{l}\text { Left Cerebral hemisphere } \\
\text { Total volume }\left(\mathrm{mm}^{3}\right) \\
\text { Volume density }(\%)\end{array}$ & $\begin{array}{c}413.48 \pm 41.82 \\
33.43 \pm 5.83\end{array}$ & $\begin{array}{c}392.75 \pm 120.76 \\
34.54 \pm 2.41\end{array}$ & $\begin{array}{c}5.28 \\
-3.21\end{array}$ & NS \\
\hline $\begin{array}{l}\text { Right Cerebral hemisphere } \\
\text { Total volume }\left(\mathrm{mm}^{3}\right) \\
\text { Volume density }(\%)\end{array}$ & $\begin{array}{c}447.61 \pm 80.47 \\
35.12 \pm 5.33\end{array}$ & $\begin{array}{c}431.65 \pm 132.94 \\
35.20 \pm 4.15\end{array}$ & $\begin{array}{l}3.69 \\
-0.23\end{array}$ & $\begin{array}{l}\text { NS } \\
\text { NS }\end{array}$ \\
\hline $\begin{array}{l}\text { Cerebellum } \\
\text { Total volume }\left(\mathrm{mm}^{3}\right) \\
\text { Volume density }(\%)\end{array}$ & $\begin{array}{c}129.7 \pm 19.53 \\
10.4 \pm 1.52\end{array}$ & $\begin{array}{c}130.3 \pm 17.24 \\
98 \pm 1.32\end{array}$ & $\begin{array}{c}-0.46 \\
6.12\end{array}$ & $\begin{array}{l}\text { NS } \\
\text { NS }\end{array}$ \\
\hline $\begin{array}{l}\text { Cerebral ventricles } \\
\text { Total volume }\left(\mathrm{mm}^{3}\right) \\
\text { Volume density }(\%) \\
\end{array}$ & $\begin{array}{c}31.02 \pm 10.02 \\
2.33 \pm 0.09 \\
\end{array}$ & $\begin{array}{c}30.33 \pm 9.33 \\
2.24 \pm 0.06 \\
\end{array}$ & $\begin{array}{l}2.27 \\
4.00 \\
\end{array}$ & $\begin{array}{l}\text { NS } \\
\text { NS }\end{array}$ \\
\hline $\begin{array}{l}\text { Left ventricle } \\
\text { Total volume }\left(\mathrm{mm}^{3}\right) \\
\text { Volume density }(\%)\end{array}$ & $\begin{array}{c}16.05 \pm 5.19 \\
1.34 \pm 0.53\end{array}$ & $\begin{array}{c}15.02 \pm 4.66 \\
1.18 \pm 0.36\end{array}$ & $\begin{array}{c}6.86 \\
13.55\end{array}$ & $\begin{array}{l}\text { NS } \\
\text { NS }\end{array}$ \\
\hline $\begin{array}{l}\text { Right ventricle } \\
\text { Total volume }\left(\mathrm{mm}^{3}\right) \\
\text { Volume density }(\%) \\
\end{array}$ & $\begin{array}{c}13.21 \pm 4.83 \\
1.12 \pm 0.47 \\
\end{array}$ & $\begin{array}{c}14.61 \pm 4.03 \\
1.12 \pm 0.29 \\
\end{array}$ & $\begin{array}{c}-9.58 \\
0.00 \\
\end{array}$ & $\begin{array}{l}\text { NS } \\
\text { NS }\end{array}$ \\
\hline $\begin{array}{l}\text { Brainstem } \\
\text { Total volume }\left(\mathrm{mm}^{3}\right) \\
\text { Volume density }(\%) \\
\end{array}$ & $\begin{array}{c}23.3 \pm 5.15 \\
1.9 \pm 0.34\end{array}$ & $\begin{array}{c}21.3 \pm 4.11 \\
1.6 \pm 0.29 \\
\end{array}$ & $\begin{array}{c}9.38 \\
18.75 \\
\end{array}$ & $\begin{array}{c}\mathrm{NS} \\
0.012 *\end{array}$ \\
\hline $\begin{array}{l}\text { Hippocampus } \\
\text { Total volume }\left(\mathrm{mm}^{3}\right) \\
\text { Volume density }(\%)\end{array}$ & $\begin{array}{l}9.75 \pm 2.53 \\
0.75 \pm 0.16\end{array}$ & $\begin{array}{l}11.1 \pm 2.89 \\
0.85 \pm 0.21\end{array}$ & $\begin{array}{l}-12.16 \\
-11.76\end{array}$ & $\begin{array}{l}\text { NS } \\
\text { NS }\end{array}$ \\
\hline $\begin{array}{l}\text { Pons } \\
\text { Total volume }\left(\mathrm{mm}^{3}\right) \\
\text { Volume density }(\%)\end{array}$ & $\begin{array}{l}10.8 \pm 3.64 \\
0.84 \pm 0.24\end{array}$ & $\begin{array}{l}10.3 \pm 3.43 \\
0.80 \pm 0.21\end{array}$ & $\begin{array}{l}4.85 \\
5.00 \\
\end{array}$ & $\begin{array}{l}\text { NS } \\
\text { NS }\end{array}$ \\
\hline $\begin{array}{l}\text { Middle cerebellar peduncle } \\
\text { Total volume }\left(\mathrm{mm}^{3}\right) \\
\text { Volume density }(\%)\end{array}$ & $\begin{array}{c}13.1 \pm 4.42 \\
1.0 \pm 0.3\end{array}$ & $\begin{array}{c}6.66 \pm 2.32 \\
0.5 \pm 0.17\end{array}$ & $\begin{array}{c}96 / 7 \\
100\end{array}$ & $\begin{array}{l}0.0001 * \\
0.0001 *\end{array}$ \\
\hline $\begin{array}{l}\text { Superior cerebellar peduncle } \\
\text { Total volume }\left(\mathrm{mm}^{3}\right) \\
\text { Volume density }(\%)\end{array}$ & $\begin{array}{l}5.21 \pm 0.72 \\
0.97 \pm 0.19\end{array}$ & $\begin{array}{l}5.29 \pm 0.88 \\
0.83 \pm 0.39\end{array}$ & $\begin{array}{l}-1.5 \\
16.87\end{array}$ & $\begin{array}{l}\text { NS } \\
\text { NS }\end{array}$ \\
\hline
\end{tabular}

NS: Not Significant

and pons in PD and healthy control groups were not statistically different. The volume density of the brain stem and total volume and volume density of middle cerebellar peduncle in PD group were significantly greater than the other group.

PD is determined as an asymmetrical and progressive disease, the symptoms mostly oc- 
curring on the affected side contralateral to the cerebral striatal lesion (21). Many studies have shown that changes in the surrounding structures of ventricles, such as hippocampus and basal ganglia may be involved in ventricular enlargement. Lewis and colleagues showed that the lateral ventricles in PD patients on the side contralateral to the symptomatic limbs got enlarged earlier and faster than the ipsilateral side. However, those asymmetries were not seen in the control group (22). Ventricular enlargement is often considered as a non-specific marker due to neurodegeneration and is associated with cognitive deficits in PD $(23,24)$. From pathophysiological point of view, a reduction in the amount of neurotransmitters projected to the higher cortical and subcortical centers such as putamen, globus pallidus, caudate nucleus, and thalamus can cause symptoms in patients. It has been suggested that a reduction in the level of neurotransmitters such as dopamine, acetylcholine and serotonin for any reason may cause volumetric changes in the surrounding structure of lateral ventricles. Malfunction of the system may show itself in the same way (25).

Results of the current study showed that total ventricular volumes and volume density of lateral ventricles were not statistically significant between PD and control groups. It seems that as the disease progresses, changes in ventricular volumes and adjacent structures become clearer but those changes cannot be considered as indicators of early diagnosis of PD.

Previous studies have shown that structural anomalies and volumetric changes of subcortical regions of the brain, may be a radiological manifestation of various neurological and neuropsychiatric disorders such as Parkinson, Alzheimer and Huntington's diseases (26). Therefore, it seems that quantitative anatomical information of involved regions can be useful and may be necessary for early diagnosis, treatment and prediction of prognosis (27).
Previous studies have shown structural changes in PD patients in different lobes of the cerebral cortex and subcortical regions. Volume reduction in cortical and subcortical areas were reported in PD patients in comparison with healthy individuals $(28,29)$. Although these qualitative studies reported volumetric changes in cerebral structures of PD patients, however, some of the MRI-based quantitative volumetric studies using point counting methods, reported that voxel-based morphometry and volumetric comparisons did not reveal significant group differences (30-32). In the current study, we used Cavalieri's point counting method and it was also shown that there were no significant differences in cerebral hemispheres and cerebellar volumes. The reason of this contradiction could be due to low sample sizes in various studies, wide variability imaging analysis techniques, use of different methods to calculate the volume with highly rater-dependent (33). However, MRI-based volumetric techniques and quantitative research are increasingly used to identify subtle changes in diagnosis, differential diagnosis by comparing them with healthy people $(17,34)$. We think that quantitative analysis based on estimation of volumetric changes is a more accurate measure for judgment and evaluation of neurodegenerative disorders compared to the qualitative analysis.

In our study there was no statistical significant difference between volumes of pons, cerebellum and superior cerebellar peduncle in both groups.

In the study of Gama et al., pons, midbrain, middle and superior cerebellar peduncle volumes in PD patients were analyzed and compared with progressive supranuclear palsy (PSP), multiple system atrophy (MSA) of the cerebellar and Parkinson variants. Their results showed that the volume of these areas were significantly higher than idiopathic PD (35). It must be emphasized that comparisons were not performed between PD and control groups. 
Paviour et al. reported total volume of the brain, frontal lobe, cerebellum, midbrain, pons, superior cerebellar peduncle, left ventricle and the third ventricle in PD patients and compared them with patients with PSP and MSA-Parkinson variants and healthy controls. The midbrain volume was significantly smaller in PSP. The frontal lobe was significantly smaller in PSP in comparison to PD and control patients. The volume of the third ventricle was prominently greater in PSP than in the control group. The lesser volume of the cerebellum and pons in MSA Parkinson variants was remarkable, too. The volume of the midbrain in MSA Parkinson variants was considerably smaller than PD and control group (36). In the above mentioned study there wasn't any statistically significant difference in the volumetric parameters. In our study the volume density was also calculated for all parts of the brain. The volume density of brainstem in PD patients was higher than the control group.

Overall, it seems that volumetric changes in different areas of the brain are likely induced by multiple factors. Those changes can be associated with compensatory processes, pathophysiological, pharmacological, disease duration, types of PD and different etiologies and other psychological disorders (37). In this regard, prospective studies are recommended to elucidate the relationship between volumetric changes of different regions of the brain and the effects of those changes on the severity of the clinical manifestation of PD symptoms. Those may help better understanding of the basic mechanisms of Parkinson's progression, diagnosis and treatment.

The results of the current study showed there were no significant differences between hippocampal volumes in PD patients and control group which is the major finding in dementia and occurs in one third of patients with PD. Hippocampus is a part of the limbic system and its performance on learning and memory is widely accepted (38). Meanwhile PD is characterized by degeneration of dopaminergic neurons. As a result of this neuronal degeneration, motor and behavioral symptoms such as tremor, rigidity and postural imbalance occurs in PD patients $(1,3)$. Neuronal loss and hippocampal atrophy mainly occur as the earliest symptoms of AD findings.

Joelving et al. stated that there was not any difference between numbers of neurons, glial cells and the volume of gray matter in the hippocampus of PD patients and the control group. Furthermore, neuronal and glial cells loss and gray matter volume of hippocampus in patients and healthy individuals are almost the same (39). Their results were consistent with our findings. Korbo et al. also reported the same and proposed that dementia might not be associated with hippocampal atrophy and cell loss (38). It seems that major atrophy in hippocampus formation and volume loss are not a part of the general pathologic picture in PD (39).

Jubault and his colleagues reported that there was a significant reduction in the volume of white matter which was overlapped with the tip of the caudal pons and rostral medulla oblongata in PD patients compared to the control group. This may be the first identifiable stage of the disease. In their patients the white matter gets atrophy by aging but there was no evidence of atrophy in gray and white matter of the brainstem (40). The results of the current study showed there were no significant differences in brainstem volumes between PD patients and control group. It has been shown that degeneration of dopaminergic neurons in substantia nigra pars compacta and ventral area of tegmentum of midbrain was the main cause of PD symptoms $(1,41)$. Thus, due to loss of dopaminergic cells in the above mentioned areas, it can be expected that reduction of gray matter volume of the brainstem particularly the midbrain occurs in PD in comparison with control subjects. In our study the brainstem volume density was significantly higher in PD patients. This may reflect the volumetric changes 
of total brain and other structures in PD patients compared to the controls.

According to the results of the present study, stereological investigations showed volumetric changes in some parts of the brain such as volume density of brainstem, total volume and volume density of middle cerebellar peduncle in patients with PD compared to the healthy group. It seems that stereological studies can be potentially used as precise and quantitative methods for early diagnosis and probably for follow-up of the treatment process in patients with PD. In this regards further studies with a larger sample size and more variables are recommended.

\section{Acknowledgements}

This manuscript is a result of the general physician's thesis (No: 90-518). Deputy of Research of Zahedan University of Medical Sciences (ZAUMS) financially supported this work. Authors appreciate all PD patients and controls who participated in the study and from Dr. Z. Rohani and S. Noora for their helps in MRI data collection.

\section{References}

1. Halliday GM, McCann H. The progression of pathology in Parkinson's disease. Annals of the New York Academy of Sciences. 2010;1184(1):188-95. DOI: 10.1111/j.1749-6632.2009.05118.x

2. Dauer W, Przedborski S. Parkinson's disease: mechanisms and models. Neuron. 2003;39(6):889-909. DOI: 10.1016/S0896-6273(03)00568-3

3. Santiago RM, Barbieiro J, Lima MM, Dombrowski PA, Andreatini R, Vital MA. Depressive-like behaviors alterations induced by intranigral MPTP, 6-OHDA, LPS and rotenone models of Parkinson's disease are predominantly associated with serotonin and dopamine. Progress in Neuro-Psychopharmacology and Biological Psychiatry. 2010;34(6):1104-14. DOI: 10.1016/j. pnpbp.2010.06.004

4. Mounsey RB, Teismann P. Mitochondrial dysfunction in Parkinson's disease: pathogenesis and neuroprotec- tion. Parkinson's Disease. 2010;2011.

5. Sato K, Hatano T, Yamashiro K, Kagohashi M, Nishioka K, Izawa N, et al. Prognosis of Parkinson's disease: time to stage III, IV, V, and to motor fluctuations. Movement disorders. 2006;21(9):1384-95. DOI: 10.1002/ mds. 20993

6. de Lau LM, Breteler MM. Epidemiology of Parkinson's disease. The Lancet Neurology. 2006;5(6):52535. DOI: 10.1016/S1474-4422(06)70471-9

7. Lolaty HA, Tirgari A, Fard JH. Emotional intelligence and related factors in medical sciences students of an Iranian university. Iranian journal of nursing and midwifery research. 2014;19(2):203.

8. Fereshtehnejad S-M, Shafieesabet M, Rahmani A, Delbari A, Lökk J. Medium-to-high prevalence of screening-detected parkinsonism in the urban area of Tehran, Iran: data from a community-based door-to-door study. Neuropsychiatric disease and treatment. 2015;11:321. DOI: $10.2147 /$ NDT.S77391

9. Tolosa E, Wenning G, Poewe W. The diagnosis of Parkinson's disease. The Lancet Neurology. 2006;5(1):7586. DOI: $10.1016 / \mathrm{S} 1474-4422(05) 70285-4$

10. Ciumas C, Montavont A, Ryvlin P. Magnetic resonance imaging in clinical trials. Current opinion in neurology. 2008;21(4):431-6. DOI: 10.1097/WCO.0b013e$3283056 \mathrm{a} 3 \mathrm{c}$

11. Halperin I, Morelli M, Korczyn AD, Youdim MB, Mandel SA. Biomarkers for evaluation of clinical efficacy of multipotential neuroprotective drugs for Alzheimer's and Parkinson's diseases. Neurotherapeutics. 2009;6(1):128-40. DOI: 10.1016/j.nurt.2008.10.033

12. Casteleyn C, Prims S, Van Cruchten S, Van Ginneken C. Stereology: from astronomy to veterinary oncology. Veterinary journal (London, England: 1997). 2014;202(1):3-4. DOI: 10.1016/j.tvj1.2014.06.001

13. Qualter P, Gardner KJ, Pope DJ, Hutchinson JM, Whiteley HE. Ability emotional intelligence, trait emotional intelligence, and academic success in British secondary schools: A 5year longitudinal study. Learning and Individual Differences. 2012;22(1):83-91. DOI: 10.1016/j. lindif.2011.11.007

14. Brannick MT, Wahi MM, Goldin SB. Psychometrics of mayer-salovey-caruso emotional intelligence test (MSCEIT) scores 1. Psychological reports. 2011;109(1):32737. DOI: 10.2466/03.04.PR0.109.4.327-337

15. Duygulu S, Hicdurmaz D, Akyar I. Nursing students' leadership and emotional intelligence in Turkey. Jour- 
nal of Nursing Education. 2011;50(5):281-5. DOI: 10.3928/01484834-20110130-07

16. Geng D-y, Li Y-X, Zee C-S. Magnetic resonance imaging-based volumetric analysis of basal ganglia nuclei and substantia nigra in patients with Parkinson's disease. Neurosurgery. 2006;58(2):256-62. DOI: 10.1227/01.NEU.0000194845.19462.7B

17. Ghaemi M, Hilker R, Rudolf J, Sobesky J, Heiss W-D. Differentiating multiple system atrophy from Parkinson's disease: contribution of striatal and midbrain MRI volumetry and multi-tracer PET imaging. Journal of Neurology, Neurosurgery \& Psychiatry. 2002;73(5):517-23. DOI: 10.1136/jnnp.73.5.517

18. Gocmen-Mas N, Pelin C, Canan S, Yazici AC, Zagyapan R, Senan S, et al. Stereological evaluation of volumetric asymmetry in healthy human cerebellum. Surgical and radiologic anatomy. 2009;31(3):177-81. DOI: 10.1007/s00276-008-0424-4

19. Heidari Z, Mahmoudzadeh-Sagheb H, Hashemi M, Rigi-Ladiz MA. Quantitative analysis of interdental Gingiva in patients with chronic periodontitis and transforming growth factor- $\beta 129 \mathrm{C} / \mathrm{T}$ gene polymorphisms. Journal of periodontology. 2014;85(2):281-9. DOI: 10.1902/jop.2013.130087

20. Heidari Z, Mahmoudzadeh-Sagheb H, Kohan F. A quantitative and qualitative study of rat testis following administration of methadone and buprenorphine. International Journal of High Risk Behaviors and Addiction. 2012;1(1):14-7. DOI: 10.5812/ijhrba.4119

21. Lee CS, Schulzer M, de la Fuente-Fernández R, Mak E, Kuramoto L, Sossi V, et al. Lack of regional selectivity during the progression of Parkinson disease: implications for pathogenesis. Archives of neurology. 2004;61(12):1920-5. DOI: 10.1001/archneur.61.12.1920

22. Lewis MM, Smith AB, Styner M, Gu H, Poole R, $\mathrm{Zhu} \mathrm{H}$, et al. Asymmetrical lateral ventricular enlargement in Parkinson's disease. European journal of neurology. 2009;16(4):475-81. DOI: 10.1111/j.14681331.2008.02430.x

23. Beyer MK, Janvin CC, Larsen JP, Aarsland D. A magnetic resonance imaging study of patients with Parkinson's disease with mild cognitive impairment and dementia using voxel-based morphometry. Journal of Neurology, Neurosurgery \& Psychiatry. 2007;78(3):254-9. DOI: 10.1136/jnnp.2006.093849

24. Nagano-Saito A, Washimi Y, Arahata Y, Kachi T, Le- rch J, Evans A, et al. Cerebral atrophy and its relation to cognitive impairment in Parkinson disease. Neurology. 2005;64(2):224-9. DOI: 10.1212/01. WNL.0000149510.41793.50

25. Fahn S, Group PS. Does levodopa slow or hasten the rate of progression of Parkinson's disease? Journal of neurology. 2005;252(4):iv37-iv42. DOI: 10.1007/ s00415-005-4008-5

26. Douaud G, Gaura V, Ribeiro M-J, Lethimonnier F, Maroy R, Verny C, et al. Distribution of grey matter atrophy in Huntington's disease patients: a combined ROI-based and voxel-based morphometric study. Neuroimage. 2006;32(4):1562-75. DOI: 10.1016/j.neuroimage.2006.05.057

27. Mamah D, Wang L, Barch D, de Erausquin GA, Gado M, Csernansky JG. Structural analysis of the basal ganglia in schizophrenia. Schizophrenia research. 2007;89(1):59-71. DOI: 10.1016/j.schres.2006.08.031

28. Summerfield C, Junqué C, Tolosa E, Salgado-Pineda P, Gómez-Ansón B, Martí MJ, et al. Structural brain changes in Parkinson disease with dementia: a voxel-based morphometry study. Archives of Neurology. 2005;62(2):281-5. DOI: 10.1001/archneur.62.2.281

29. Cordato N, Duggins A, Halliday G, Morris J, Pantelis C. Clinical deficits correlate with regional cerebral atrophy in progressive supranuclear palsy. Brain. 2005;128(6):1259-66. DOI: 10.1093/brain/awh508

30. Menke RA, Szewczyk-Krolikowski K, Jbabdi S, Jenkinson M, Talbot K, Mackay CE, et al. Comprehensive morphometry of subcortical grey matter structures in early-stage Parkinson's disease. Human brain mapping. 2014;35(4):1681-90. DOI: 10.1002/hbm.22282

31. Sterling NW, Du G, Lewis MM, Dimaio C, Kong L, Eslinger PJ, et al. Striatal shape in Parkinson's disease. Neurobiology of aging. 2013;34(11):2510-6. DOI: 10.1016/j.neurobiolaging.2013.05.017

32. Quattrone A, Nicoletti G, Messina D, Fera F, Condino F, Pugliese $P$, et al. MR imaging index for differentiation of progressive supranuclear palsy from parkinson disease and the parkinson variant of multiple system atrophy 1. Radiology. 2008;246(1):214-21. DOI: 10.1148/radiol.2453061703

33. Acharya HJ, Bouchard TP, Emery DJ, Camicioli RM. Axial signs and magnetic resonance imaging correlates in Parkinson's disease. The Canadian Journal of Neurological Sciences. 2007;34(01):56-61. DOI: 10.1017/ S0317167100005795 
34. Hu M, White S, Chaudhuri KR, Morris R, Bydder G, Brooks D. Correlating rates of cerebral atrophy in Parkinson's disease with measures of cognitive decline. Journal of neural transmission. 2001;108(5):571-80. DOI: $10.1007 / \mathrm{s} 007020170057$

35. Gama RL, Távora DF, Bomfim RC, Silva CE, Bruin VMd, Bruin PFd. Morphometry MRI in the differential diagnosis of parkinsonian syndromes. Arquivos de neuro-psiquiatria. 2010;68(3):333-8. DOI: 10.1590/S0004282X2010000300001

36. Paviour DC, Price SL, Jahanshahi M, Lees AJ, Fox NC. Regional brain volumes distinguish PSP, MSA-P, and PD: MRI-based clinico-radiological correlations. Movement disorders. 2006;21(7):989-96. DOI: 10.1002/mds. 20877

37. Ertekin T, Acer N, İçer S, Vurdem ÜE, Çınar Ş, Özçelik Ö. Volume estimation of the subcortical structures in Parkinson's disease using magnetic resonance imaging: A methodological study. Neurology Asia.
2015;20(2):143-53.

38. Korbo L, Amrein I, Lipp HP, Wolfer D, Regeur L, Oster S, et al. No evidence for loss of hippocampal neurons in non-Alzheimer dementia patients. Acta neurologica scandinavica. 2004;109(2):132-9. DOI: 10.1034/j.1600-0404.2003.00182.x

39. Joelving F, Billeskov R, Christensen J, West M, Pakkenberg B. Hippocampal neuron and glial cell numbers in Parkinson's disease - a stereological study. Hippocampus. 2006;16(10):826-33. DOI: 10.1002/hipo.20212

40. Jubault T, Brambati SM, Degroot C, Kullmann B, Strafella AP, Lafontaine A-L, et al. Regional brain stem atrophy in idiopathic Parkinson's disease detected by anatomical MRI. PloS one. 2009;4(12):e8247. DOI: 10.1371/journal.pone. 0008247

41. Toulouse A, Sullivan AM. Progress in Parkinson's disease - where do we stand? Progress in neurobiology. 2008;85(4):376-92. DOI: 10.1016/j.pneurobio.2008.05.003 